Proceedings of SALT 22: 326-346, 2012

\title{
A multistratal account of the projective Tagalog evidential 'daw'*
}

\author{
Gregory Kierstead \\ Ohio State University
}

\author{
Scott Martin \\ Ohio State University
}

\begin{abstract}
We present original fieldwork data as evidence that the Tagalog reportative evidential daw projects, like e.g. presuppositions and conventional implicatures (CIs), in the sense that daw can carry an implication that is immune to entailmentmodifying operators. Previous work has purported that evidentials in other languages can project, but after examining these claims, we argue that the data we give for daw constitute the first evidence of a projective evidential. We then give a formally explicit account of daw in a multistratal semantics that is both dynamic and compositional. This semantics is general enough to also capture the behavior of English CIs, but avoids a well-known flaw in a previous theory of CIs due to Potts.
\end{abstract}

Keywords: Tagalog daw, evidentiality, projection, type theory, dynamic semantics

\section{Introduction}

The phenomenon of projection, exemplified by the nominal appositive in (1) below, poses a challenge for formal semantic analysis. An utterance of (1a) implies (at least) two things: that Emily is a chef, and that she is from Rhode Island. In (1b), this sentence is embedded under a modal, and the resulting utterance no longer implies that Emily is from Rhode Island, but still implies that she is a chef:

a. Emily, a chef, is from Rhode Island.

b. Maybe Emily, a chef, is from Rhode Island.

As the implication that Emily is a chef, a conventional implicature (CI) in Potts's (2005) terms, survives although its corresponding constituent is embedded under an operator that modifies entailments, it projects (Simons, Roberts, Beaver \& Tonhauser 2010). The challenge is to explain what is special about the projective implication that makes it survive, unlike the implication that Emily is from Rhode Island.

* For valuable comments, we thank Chris Barker, Michelle Dionisio, Yusuke Kubota, Dan Lassiter, Carl Pollard, Craige Roberts, Magdalena Schwager, Judith Tonhauser, the participants of Synners (the OSU working group on syntax and semantics), the SALT 2012 participants, and the anonymous reviewers. We would also like to thank informants Michelle Dionisio, Robert de Guzman, and Michael Sansait. Gregory Kierstead was supported by NSF grant 0952571. 
A multistratal account of the projective Tagalog evidential 'daw'

So far, there has been no clear evidence that the class of projective meanings overlaps the class of evidentials: grammatical items whose primary meaning is to denote evidence source. In Cusco Quechua, for example, -si implies a speaker has reportative evidence for the proposition expressed (Faller 2002) and thus it is a reportative evidential.

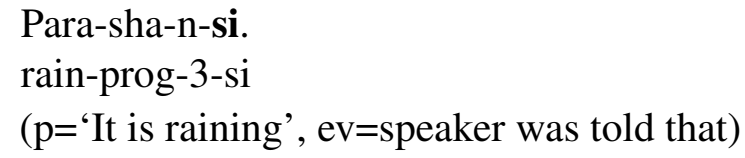

(Faller 2002: 3)

In this paper we present original fieldwork data on the Tagalog reportative evidential daw, showing that it is associated with an implication that projects. While evidentials in other languages have been purported to project, we show these examples do not provide conclusive evidence for projection, and thus the data on daw is the first clear evidence of an evidential associated with a projective implication. As such, the data on daw enhances our knowledge of the space of projective meaning. Furthermore, we show that the projection behavior is context dependent in a way not attested previously in the literature, showing the class of projective meanings may be more diverse than previously thought.

To formalize these observations, we build on de Groote 2006 by giving an analysis of daw in a multistratal semantics that preserves the insights of traditional dynamic theories, but is also compositional and grounded in a mainstream, wellunderstood mathematical formalism. The multistratal approach we adopt allows us to give an account of daw that extends to other instances of projective meaning such as the English nominal appositive discussed in (1), above. In a sense, our formal treatment of projection generalizes Potts's (2005) account of CIs in that both projective and non-projective content are available at each compositional step, following Nouwen (2007).

In $\S 2$, we give some examples from our Tagalog fieldwork that show that daw is a reportative evidential that can have a projective implication that is sometimes dependent on context. Previous analyses of evidentials, including ones that purport to show evidence of projection, are discussed in $\S 3$. Our formal account of $d a w$ is presented in $\S 4$, in the context of a broader semantic framework that can capture the projection associated with English appositives. Finally, §5 concludes and points out directions for future work.

\section{Tagalog Data}

Tagalog is a language spoken in the Philippines and is one of the two national languages (the other being English). It is spoken by over 21 million people in the Philippines and over 23 million in total (Lewis 2009). It is a predicate initial 
language, with predicates marked for voice and aspect. Daw is a second-position particle, meaning that in a sentence consisting of a predicate and its arguments, daw appears after the predicate and before its complements (Schwager 2010). Thus, in the following example, daw is acceptable only in the position it appears in, and placement in any other position results in ungrammaticality. Use of daw implies that the proposition expressed was reported, e.g. in (3), that there was a report that Paul ate adobo (a traditional Filipino stew). ${ }^{1}$

$$
\begin{aligned}
& \text { Kumain daw si Paul ng adobo. } \\
& \text { eat.PERF.AV RPT DIR Paul IND adobo } \\
& \text { 'It was reported that Paul ate the adobo.' }
\end{aligned}
$$

As utterances with daw imply the existence of a report, daw is a reportative evidential, i.e., when added to a simple declarative with propositional content $\phi$, daw "expresses that $\phi$ has been asserted previously by some source $x$ " (Schwager 2010). Thus, there are (at least) two implications associated with an utterance containing daw: e.g., in (3) the implication that Paul ate adobo, and the implication that this is based upon the report of some external source. The former we will call the prejacent implication, and the latter the reportative implication.

In a simple declarative, the speaker is necessarily committed to the reportative implication. For example, use of $d a w$ in (4) is acceptable because Phil heard a weather report; in a minimally different context where Phil did not hear a report, consultants find daw unacceptable.

Context Phil, who lives in Ohio, has been inside all of yesterday and today, in his windowless apartment, working. He watches the weather report on the news, which says it rained yesterday. He calls his friend Sam who lives in California. He starts the conversation by saying:

\section{Umulan daw kahapon. \\ rain.PERF RPT yesterday}

'It was reported that it rained yesterday.'

Use of $d a w$ requires reportative evidence specifically: in minimally different contexts where Phil learned it was raining by either (i) being outside and seeing it, (ii) hearing the sound on the roof, or (iii) seeing other people in the apartment building come in with raincoats and umbrellas that are dripping wet, consultants found daw

1 All Tagalog data reported here is from original fieldwork, unless stated otherwise. We use the following glosses here: $\mathrm{RPT}=$ reportative evidential, $\mathrm{DIR}=$ direct case marker, IND=indirect case marker, $\mathrm{AV}=$ agent voice, $\mathrm{PV}=$ patient voice, $\mathrm{PERF}=$ perfective aspect, IMPERF=imperfective aspect, $\mathrm{CONT}=$ contemplative aspect, $\mathrm{INF}=$ infinitive, $\mathrm{LK}=$ linker particle, $\mathrm{PL}=$ plural marker, $\mathrm{INCL}=$ inclusive, $\mathrm{HON}=$ honorific. 
A multistratal account of the projective Tagalog evidential 'daw'

unacceptable. Thus, daw is a reportative, and not a direct, indirect or inferential evidential.

Notice that the reportative implication of daw in (4) is new information: Phil starts the conversation with (4), and thus it is not in Phil and Sam's common ground that there was a weather report, as Phil has not mentioned the weather report before (4), and Sam would not have watched the Ohio news weather report from where he lives in California.

With respect to the prejacent implication, it may or may not be implied depending on context. In an enriched context, where it is common knowledge that the weather reports Phil listens to are always correct, then consultants find (4) to imply that it did actually rain. However, the prejacent implication need not be implied: in a differently enriched context, where the weather reports are frequently wrong, (4) is still acceptable, but consultants report that it does not give any indication whether it actually rained or not. Thus, in a context with enough information, an utterance with daw implies both the reportative and prejacent implications, but absent this extra information, only the reportative implication is implied.

\subsection{The modal baka 'maybe'}

We will consider cases of daw embedded under the modal baka 'maybe'. Before considering utterances with baka 'maybe' and daw, we first consider baka on its own. Baka 'maybe' is a sentential modifier, and occurs sentence initially:

[Baka [kumain si Paulng adobo. $\left.]_{S}\right]_{S}$

maybe eat.PERF.AV DIR Paul IND adobo

'Maybe Paul ate the adobo.'

We assume, as seen from the brackets given above, that the structure in (5) includes an embedded sentential clause, and so everything contained within that clause is syntactically embedded under baka 'maybe'. Kroeger (1993) devises a test for clause boundaries based on the placement of pronouns, which like daw, are second position particles. As pronouns occur in the second position of the clause in which they are an argument, their position can be used to diagnose the existence of a clause boundary. For example, the position of ako 'I' is evidence of a clause boundary preceding bibili 'buy':

$$
\begin{aligned}
& \text { a. } \left.[\text { Baka [bibili ako ng bahay ni Linda. }]_{S}\right]_{S} \\
& \text { maybe buy.AV.CONT 1SG.DIR IND house IND Linda } \\
& \text { 'I might buy Linda's house.' } \\
& \text { b. * } \text { Baka ako bibili } \\
& \text { maybe 1SG.DIR buy.AV.CONT IND house IND Linda }
\end{aligned}
$$


Intended: 'I might buy Linda's house.'

As the pronoun must come after the predicate bibili 'buy', and cannot appear after baka 'maybe' directly, this gives evidence of an embedded clause: assuming that bibili 'buy' is the start of a embedded sentential clause explains the position of ako 'I' in that it occurs as the second item of the clause that contains it. The ungrammaticality of (6b) can be explained because ako ' $\mathrm{I}$ ' is a semantic argument of bibili 'buy', but does not occur in the same clause as it.

Now that we have shown baka 'maybe' is an embedding predicate, we turn to utterances containing both daw and baka 'maybe'. In such utterances, daw can appear directly after baka 'maybe', or after the embedded predicate, but not in any other positions. One possible reading when daw appears in either of these positions is that it has wide scope over baka 'maybe'. In (8), use of daw implies the existence of a previous report that maybe Eric ate Bill's chocolate bar, i.e., the report Bill hears from Sam: (DAW(MAYBE(p)).

Context Bill lives in a house with roommates Sam and Eric. One day he leaves for work, and comes home to find someone else in the house has eaten a chocolate bar he had been saving in the fridge. He goes to ask Sam if he knows what happened to it. Sam says:

Baka kumain si Eric ng tsokolate mo.

maybe eat.PERF.AV DIR Eric IND chocolate 2SG.IND

'Maybe Eric ate your chocolate bar.'

Bill later tells his mother that his chocolate bar was stolen, and he's not sure who ate it, but says:

a. Baka kumain daw si Eric ng tsokolate ko. maybe eat.PERF.AV RPT DIR Eric IND chocolate 1SG.IND

b. Baka daw kumain si Eric ng tsokolate ko. maybe RPT eat.PERF.AV DIR Eric IND chocolate 1SG.IND

'It was reported that maybe Eric ate my chocolate bar.'

Similar to the unembedded example (4), the prejacent implication of (8), MAYBE(p), is not implied. However, in an enriched context where it is common knowledge that Sam's reports are trustworthy, the prejacent implication would be implied. In this special context, we would thus get a reading DAW(MAYBE(p))^MAYBE(p). This reading involves projection, only with the implication MAYBE $\mathrm{p}$ instead of the reportative implication (see the discussion of (11), below).

When daw appears after the embedded predicate, another scope interpretation is possible, where daw takes narrow scope with respect to baka 'maybe'. The reading is that there is a possibility of something being reported: (MAYBE(DAW(p))). 
A multistratal account of the projective Tagalog evidential 'daw'

Context Jane and Sally are watching the TV, and the news is about to come on. They are guessing what the weather report will say. Jane says:

Baka uulan daw bukas.

maybe rain.CONT RPT tomorrow

'Maybe it will say it will rain tomorrow.'

As the context is such that there is no actual report, but just the possibility that there will be one, the narrow scope interpretation is the only one possible, as the wide scope interpretation would involve a false implication. In (9) above, daw must appear after the embedded predicate uulan 'rain'; if daw appears directly after baka in this context, it results in unacceptability.

Another reading is possible when daw appears after the embedded predicate, where the reportative implication of daw projects. I.e., in (11), use of daw implies that the prejacent, that Eric ate the candy bar, was actually reported, even though daw appears embedded under the modal baka 'maybe': (DAW p $\wedge$ MAYBE(p)).

Context Bill lives in a house with roommates Sam and Eric. One day he leaves for work, and comes home to find someone else in the house has eaten a chocolate bar he had been saving in the fridge. He goes to ask Sam if he knows what happened to it. Sam says:

(10) Kumain si Eric ng tsokolate mo. eat.PERF.AV DIR Eric IND chocolate 2SG.IND

'Eric ate your chocolate bar.'

Bill thinks maybe Sam is telling the truth, but maybe Sam ate it, and so is lying about the chocolate. Bill later tells his mother that his chocolate bar was stolen, and he's not sure who ate it, but says:

\section{Baka kumain daw si Eric ng tsokolate ko.} maybe eat.PERF.AV RPT DIR Eric IND chocolate 1SG.IND

'Maybe Eric ate my chocolate bar, as it was reported he did.'

Further evidence that $d a w$ in (11) implies it was reported that Eric ate the candy bar comes from consultants finding use of $d a w$ unacceptable in a minimally different context where Bill does not hear any report, presumably because use of daw in such a context would give rise to a false implication. Thus, it is the use of daw in particular that gives rise to the implication of a report, and so its reportative implication projects. Additionally, daw cannot appear directly after baka 'maybe' in the context in (11), showing the projective reading is not available when daw appears in this position. 
Gregory Kierstead and Scott Martin

\begin{tabular}{|l|ll|}
\hline Position of daw & Readings \\
\hline \hline After baka & WS & WS $\wedge$ MAYBE $\mathrm{p}$ \\
& DAW(MAYBE $\mathrm{p})$ & DAW(MAYBE $\mathrm{p}) \wedge$ MAYBE $\mathrm{p}$ \\
\hline After embedded pred. & WS & WS $\wedge$ MAYBE $\mathrm{p}$ \\
& DAW(MAYBE $\mathrm{p})$ & DAW(MAYBE $\mathrm{p}) \wedge$ MAYBE $\mathrm{p}$ \\
& $\mathrm{NS}$ & $\mathrm{P}$ \\
& $\mathrm{MAYBE}(\mathrm{DAW} \mathrm{p})$ & DAW $\mathrm{p} \wedge$ MAYBE $\mathrm{p}$ \\
\hline
\end{tabular}

Table 1 Summary of readings of daw with baka.

To summarize, we have seen that when daw appears with the modal baka 'maybe', depending on context and placement of daw, one of four readings are possible: if daw occurs directly after baka 'maybe', daw must take wide scope. If daw occurs after the embedded predicate, the wide scope (WS) reading is also possible. For both of these positions, in contexts where the report is trustworthy, the reading DAW(MAYBE $\mathrm{p}) \wedge$ MAYBE $\mathrm{p}$ is observed. When daw appears after the embedded predicate, two additional readings are possible: one where daw takes narrow scope (NS) with respect to baka 'maybe', and another where the reportative implication of daw projects $(\mathrm{P})$. These readings are summarized in Table 1.

\section{Previous Analyses}

The data previously considered has shown that depending on context, the reportative implication of $d a w$ can project, or daw can take wide or narrow scope with respect to the embedding operator. As most previous analyses of evidentials did not find evidence for a projective implication associated with an evidential, the analyses proposed are not adequate for modeling daw.

For example, Faller (2002) analyzes evidentials in Cusco Quechua as modifying an entire speech act. This explains why evidentials in Cusco Quechua cannot be embedded in general, as they must operate on an entire speech act. However, as we have seen that daw can be embedded, this analysis will not work for daw.

Other evidentials have been shown to be embeddable: Matthewson, Davis \& Rullman (2007) show evidentials in St'át'imcets can take narrow scope under propositional attitude verbs, and McCready \& Ogata (2007) show evidentials in Japanese can take narrow scope in the antecedent of a conditional. Neither find any evidence of a projective reading in these languages. Both pursue modal analyses, which explains the embedded behavior. However, simply having a modal analysis will not explain the projective behavior seen with daw; more machinery is required. 
A multistratal account of the projective Tagalog evidential 'daw'

Murray (2010) gives an analysis of Cheyenne utterances with evidentials as contributing a negotiable and non-negotiable update to the common ground. This analysis is also used by Lee (2011) for Korean evidentials. While neither Cheyenne nor Korean give evidence for projection of evidential implications, Murray notes that such a framework could capture projective behavior, although not in a compositional way. The analysis we propose captures the projective behavior compositionally.

While McCready \& Ogata do not find evidence for projection with Japanese evidentials, they do propose that evidentials in Quechua can project. In (12), even when embedded in the consequent of a conditional, use of the reportative evidential -si seems to imply there was a report, suggesting projection:

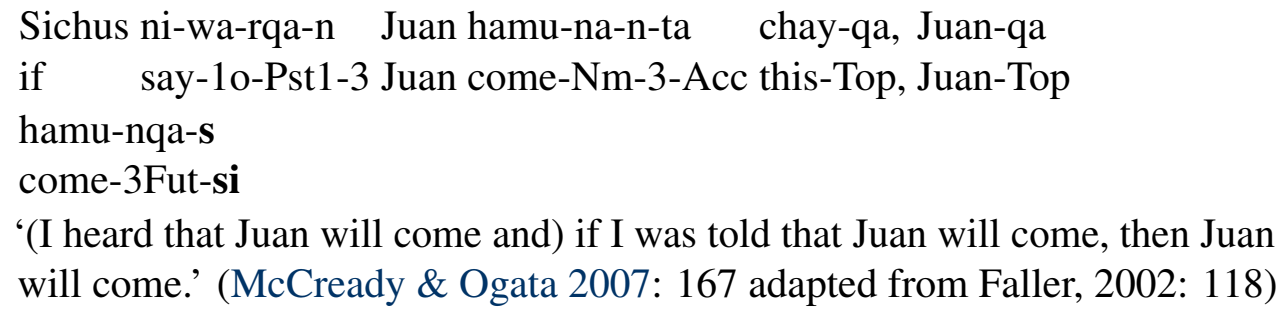

This reading could be represented schematically as: RPT $\mathrm{p} \wedge$ if $\mathrm{p}$ then $\mathrm{q}$, where the reportative implication (RPT p) projects. However, it is not clear that (12) implies there was a report: as the example is given without either context or discussion of consultants' comments, the only evidence is the translation. Following Matthewson (2004: 377) we assume "translations are insufficient to determine whether the analysis is right," and thus solely the translation of a single example is insufficient to show that the implication is projective.

A projective reading is also hinted at in Schwager 2010: 239 for $d a w$, when embedded under the modal hindi marahil 'not probable':

Hindi marahil na naging guro daw niya si Legrenzi. not probable LK was teacher RPT 3SG.IND DIR Legrenzi.

'That Legrenzi had been his teacher (as it is alleged), is unlikely.'

Again, the reading is schematically RPT $\mathrm{p} \wedge$ NOT PROBABLE $\mathrm{p}$ : the reportative implication is independent from the modal, and so it projects. Again, however, this evidence is based only upon the translation, which we do not take to be sufficient. ${ }^{2}$ We propose that the fieldwork data shown previously based just upon felicity judgments is much stronger evidence for projectivity. Schwager (2010) also gives an analysis of daw as a presupposition trigger, giving rise to presuppositions "of the form 'some $x$ said $p$ '." She goes on to specify that, essentially, this is an anaphoric presupposition, requiring as antecedent an event $e$ where $x$ is the agent and the event

2 The translation is actually given as a joint translation for the Tagalog sentence with daw and a similar German sentence with sollen. 
is $x$ making an utterance with content $p$. Thus, as use of daw would place a constraint on prior context, requiring some agent to have previously uttered $p$, this would be in the common ground, and so it would not be affected by embedding operators.

However, as seen previously in (4), the reportative implication of daw can be new information, and so this proposed presupposition associated with daw need not have an antecedent event in prior context. In order to capture such data while still assuming a presuppositional analysis, we would need to assume that the presupposition triggered by daw could be accommodated (Lewis 1979; van der Sandt 1992). Simons et al. (2010) take issue with this kind of analysis, in which a projective meaning is analyzed as a presupposition that is often accommodated. They point out that there is "evidence that true common ground constraints are in fact not amenable to accommodation," giving as paradigm examples too and pronouns:

(14) If she didn't sleep in the hammock, I don't know where she slept. (Simons et al. 2010: example 10)

Use of she is felicitous only if there is a unique woman salient in the common ground. If no such woman exists, a listener cannot accommodate the fact that this woman exists; the utterance is just infelicitous. Simons et al. thus conclude that it is "conceptually problematic to treat accommodation of common ground constraints as the norm" for these sorts of projective meaning triggers. We adopt the stance that the reportative implication is not a presupposition, and thus daw is not a presupposition trigger; it is instead an instance of non-presuppositional projective meaning.

\section{The Account}

We express our account of daw in a dynamic semantics inspired by de Groote (2006), which couples the insights of early dynamic theories (Kamp 1981; Heim 1982; Groenendijk \& Stokhof 1991) with Montagovian derivational compositionality in a tradition that includes Muskens 1996 and Beaver 2001. Our semantics updates previous work on dynamically handling presuppositions (Martin 2012; Martin \& Pollard 2012) in two important respects. First, its dynamics are simplified so that de Groote's continuations are no longer needed. And second, it essentially follows Heim (1982) in that indefinites introduce variables that are lambda bound, rather than existentially bound as in e.g. Groenendijk \& Stokhof's and de Groote's theories.

In contrast with Barker \& Shan 2008 and Kubota \& Uegaki 2009, which account for utterance-level meaning, our theory presents a broader view of the modeling of dynamic meaning in that it has an explicit model of the discourse context. Our theory can be thought of as a generalization of Potts 2005 in which both "at-issue" and not-at-issue content figure into each compositional step, rather than not-at-issue content merely being available at the utterance level, as for Potts. In this way, we 
A multistratal account of the projective Tagalog evidential 'daw'

repair the critical flaw in Potts's theory pointed out by Amaral, Roberts \& Smith (2007): that it does not allow anaphora between at-issue and not-at-issue content.

With its multistratal architecture, it is also similar to Nouwen's (2007) twodimensional dynamic semantics (and the extension of it sketched in AnderBois, Brasoveanu \& Henderson 2010). Like Nouwen's theory, it is capable of capturing the infelicity of quantified appositives, as demonstrated by the examples in (15).

(15) a. A Dutch boxer, a famous one, takes part in the event.

b. \# Every Dutch boxer, a famous one, takes part in the event.

(Nouwen 2007: example 6)

(We do not discuss quantified appositives further here, as it would take us too far afield.) However, our theory is more general than Nouwen's in that e.g. multiple embeddings of appositives (cf. 16) are not ruled out.

(16) Leo, $\langle$ a lion, $\langle$ a mighty species $\rangle$,$\rangle swallowed the trainer whole. (Potts 2005:$ example 4.25 , brackets ours)

For Nouwen, more than one level of embedding is explicitly forbidden.

\subsection{Formal System}

The underlying formal system is a mainstream classical type theory in the tradition of Church (1940), Henkin (1950), Carpenter (1997) and Andrews (2002). This system, also known as higher-order logic, is similar to the simply typed lambda calculus, but the relations of $\alpha \beta \eta$-conversion are internalized into the object language by adding equality symbols for all types and then stating suitable axioms for term equality (see Andrews 2002: chapter 5 for details).

As usual, there are two basic types, $\imath$ (of individuals) and $o$ (of truth values), which we write as e and t, respectively, in accordance with standard practice in semantics. We also make use of the natural number type $\omega$, defined as usual with the corresponding linear order $<$ and (infix) binary addition operator + . Types are recursively built using $\rightarrow$ and $\times$, so that if $A$ and $B$ are types, so are $A \rightarrow B$ and $A \times B$. Lastly, we allow dependent types parameterized by the natural numbers, but do not go into formal detail about them here (see Barendregt 1991 for a comprehensive overview of dependent typing).

For each type $A$, there is the usual countably infinite set $x_{0}^{A}, x_{1}^{A}, \ldots$ of variables of type $A$, usually written e.g. $x, y, z$ when the types are clear from context. In addition to the logical equality constants $={ }_{A}$ for each type $A$, nonlogical constants are definable (and are central to stating our semantic theory, below). A typing declaration of the form $a: A$ is interpreted as saying that $a$ is a term with type $A$. The recursive clauses for term formation are as follows, where as usual, $\lambda$ is a variable binder and $\pi_{1}$ and $\pi_{2}$ are respectively the first and second projection functions: 


$$
\begin{aligned}
\vdash c: A \quad \text { (Const) } & x: A \vdash x: A \quad \text { (Var) } x \text { fresh } \\
\frac{\Gamma, x: A \vdash b: B}{\Gamma \vdash\left(\lambda_{x} b\right): A \rightarrow B}(\rightarrow \mathrm{I}) & \frac{\Gamma \vdash f: A \rightarrow B \quad \Delta \vdash a: A}{\Gamma, \Delta \vdash(\text { fa }): B}(\rightarrow \mathrm{E}) \\
\frac{\Gamma \vdash a: A \quad \Delta \vdash b: B}{\Gamma, \Delta \vdash\langle a, b\rangle: A \times B}(\times \mathrm{I}) & \frac{\Gamma \vdash M: T_{1} \times T_{2}}{\Gamma \vdash\left(\pi_{i} M\right): T_{i}}\left(\times \mathrm{E}_{i}\right) \quad i \in\{1,2\}
\end{aligned}
$$

Figure 1 Natural deduction rule schemas.

i. If $x: A$ is a variable and $b: B$, then $\left(\lambda_{x} b\right): A \rightarrow B$.

ii. If $f: A \rightarrow B$ and $a: A$, then $(f a): B$.

iii. If $a: A$ and $b: B$, then $\langle a, b\rangle: A \times B$.

iv. If $M: A \times B$, then $\left(\pi_{1} M\right): A$ and $\left(\pi_{2} M\right): B$.

A (variable) context $\Gamma$ is a set of variables, with $\Gamma, x: A$ shorthand for $\Gamma \cup\{x: A\}$. A typing judgment of the form $\Gamma \vdash a: A$ is a metalanguage statement that $a$ is judged to have the type $A$ in the context $\Gamma$. In case $\Gamma$ is empty, then $a: A$ is a theorem of the logic and we write simply $\vdash a: A$. We sometimes write judgments of the form $\Gamma \vdash a={ }_{A} b: A$ to express that the terms $a$ and $b$ are equal and have the type $A$. In practice we always omit the type subscript on the equality symbol = when typing information is available from context.

The inference rules of the type system are given in a natural deduction presentation in Figure 1. The Const and Var rules handle the introduction of constants and variables, respectively, with the proviso that each use of Var introduces an as-yet-unused variable. Hypothetical proof and modus ponens are modeled by $\rightarrow I$ and $\rightarrow \mathrm{E}$, and the rules for pairing are $\times \mathrm{I}$ and $\times \mathrm{E}_{i}$. For reasons of space, we omit proof trees from this paper since they can be reconstructed from the terms.

We observe the usual notational convention that a single period (.) abbreviates a pair of parentheses with the omitted right parenthesis as far to the right as possible, so that $\lambda_{x} . f$ is shorthand for $\left(\lambda_{x} f\right)$. Parentheses associate to the left, with $(f x y)$ abbreviating $((f x) y)$, and are often omitted altogether when no confusion can arise. We also sometimes collapse multiple variable bindings onto a single $\lambda$ symbol: e.g., we write $\lambda_{x y} . f$ for $\lambda_{x} \lambda_{y} . f$. Lastly, we write $=$ def to signal definitional equality, distinguishing it from the logical equality constants $={ }_{A}$. 
A multistratal account of the projective Tagalog evidential 'daw'

\subsection{A Multistratal Dynamic Semantics}

For static semantics, we add the types $\mathrm{p}$ (of propositions) and w (of worlds), but we remain agnostic in the sense of Plummer \& Pollard (2012) as to whether the type $p$ is basic or, as in standard possible worlds semantics, defined as (characteristic functions of) sets of worlds. We define $\mathrm{e} \rightarrow \mathrm{p}$ and $\mathrm{e} \rightarrow \mathrm{e} \rightarrow \mathrm{p}$ as the types of unary and binary static properties, respectively. We also adopt from Plummer \& Pollard the necessary truth true $: p$, the propositional connectives and $: p \rightarrow p \rightarrow p$ and not $: p \rightarrow p$, and the quantifier exists : $(\mathrm{e} \rightarrow \mathrm{p}) \rightarrow \mathrm{p}$, along with the corresponding axioms for their truth conditions at a given world. As a notational convenience, we write (exists $x P$ ) as shorthand for (exists $\lambda_{x} . P$ ), for $P$ a unary static property.

We define the type $\mathrm{e}^{n}={ }_{\text {def }} \omega_{n} \rightarrow \mathrm{e}$ of strings of individuals, where $\omega_{n}$ is the type of natural numbers less than $n$, by analogy with Heim's (1982) "sequences." Vector notation is used to reference strings and their components, so that if $\mathbf{x}: \mathrm{e}^{n}$ is an $n$-length string of individuals, the individual $\mathbf{x}_{i}$ is the $i$-th component of $\mathbf{x}$ (i.e., the value of $\mathbf{x}$ at $i$ ) for $0 \leq i<n$. These component indices, which we will refer to as coordinates, play the role of discourse referents (DRs) in our dynamic semantics. For two strings $\mathbf{x}: \mathrm{e}^{n}$ and $\mathbf{y}: \mathrm{e}^{m}$, we sometimes write $\mathbf{x}, \mathbf{y}$ to denote the concatenation of $\mathbf{x}$ and $\mathbf{y}$, which has type $\mathrm{e}^{n+m}$. As shorthand, we sometimes write e.g. $\mathbf{x}^{n}$ to indicate that $\mathbf{x}$ has type $\mathrm{e}^{n}$ when the typing information is otherwise unclear. We also assume that the existential quantifier exists extends from unary properties to strings of individuals in the obvious way.

\subsubsection{Contexts and Contents}

The type of (discourse) contexts is the type of functions from a string of individuals to a pair of propositions:

$$
\mathrm{c}_{n, m}={ }_{\text {def }} \mathrm{e}^{n+m} \rightarrow(\mathrm{p} \times \mathrm{p}) .
$$

In a context of type $c_{n, m}$, the first component of the consequent $\mathrm{p} \times \mathrm{p}$ is the global stratum, and the second is the local stratum. The natural number parameters $n$ and $m$ are to be interpreted as saying that $c$ 's global stratum pertains to the first $n$ DRs only, and the local one (possibly) pertains to all $n+m$ DRs (the dynamic connectives, defined in $\$ 4.2 .2$ below, enforce this partitioning). To reduce clutter, we write the term corresponding to the pair of propositions in the consequent as $p \mid q$ rather than $\langle p, q\rangle$. For example, in the example context

$$
\left.e=\lambda_{x, y} .(\text { farmer } x) \mid(\text { donkey } y) \text { and (own } y x\right),
$$

the global stratum of $e$ contains the proposition (farmer $x$ ), and the local one contains (donkey $y$ ) and (own $y x$ ), where donkey, farmer, and own are defined as static properties. 
The parameters of a context $c: c_{n, m}$ are accessible as follows:

$$
\bar{c}={ }_{\operatorname{def}} n={ }_{\operatorname{def}} m,
$$

with the arity of $c$ defined as the sum of its parameters

$$
|c|={ }_{\operatorname{def}} \bar{c}+\underline{c} .
$$

The global and local strata of $c$ are accessed by $\uparrow: \mathrm{c}_{n, m} \rightarrow\left(\mathrm{e}^{n+m} \rightarrow \mathrm{p}\right)$ and $\downarrow: \mathrm{c}_{n, m} \rightarrow$ $\left(\mathrm{e}^{n+m} \rightarrow \mathrm{p}\right)$, respectively:

$$
(\uparrow c)={ }_{\text {def }} \lambda_{\mathbf{x}^{|c|}} \cdot \pi_{1}(c \mathbf{x}) \quad(\downarrow c)={ }_{\text {def }} \lambda_{\mathbf{x}^{|c|}} \cdot \pi_{2}(c \mathbf{x}) .
$$

As an example, for the context $e$ in Equation (17), these functions give

$$
(\uparrow e)=\lambda_{x, y} .(\text { farmer } x) \quad(\downarrow e)=\lambda_{x, y} .(\text { donkey } y) \text { and }(\text { own } y x)
$$

as the global and local strata.

Dynamic meanings, which we call (proffered) contents following Roberts (1996), are modeled by the type

$$
\mathrm{k}_{i, j}={ }_{\text {def }} \mathrm{c}_{n, m} \rightarrow \mathrm{c}_{n+i, m+j}
$$

of functions from contexts to contexts. ${ }^{3}$ The parameters $i$ and $j$ on a content $k: \mathrm{k}_{i, j}$, called its global and local degree, respectively, are the number of DRs that $k$ introduces into the two strata. They have the effect that if $k$ 's input context pertains to $n$ global DRs and $m$ local ones, then the global stratum of its output context pertains to $n+i$ DRs and the local stratum of its output context to $m+j$ DRs. Similarly to contexts, the parameters of a content $k: \mathrm{k}_{i, j}$ are accessible via

$$
\bar{k}={ }_{\mathrm{def}} i
$$

and similarly to contexts, its degree is given as the parameters' sum

$$
|k|=\operatorname{def} \bar{k}+\underline{k} .
$$

3 Martin \& Pollard (2012) define proffered contents as partial operations on contexts in order to construe presuppositions as contextual constraints. Since presuppositions lie outside the scope of this paper, we avoid the additional formal complexity introduced by partiality by using total functions instead. 
A multistratal account of the projective Tagalog evidential 'daw'

Dynamic properties are then simply functions from a DR (i.e., a natural number) to a proffered content, with type $\omega \rightarrow \mathrm{k}_{0,0}$. For example, the dynamic property

$$
\text { DONKEY }={ }_{\text {def }} \lambda_{n c} \lambda_{\mathbf{x}^{\bar{c}}} \text {.true } \mid\left(\text { donkey } \mathbf{x}_{n}\right)
$$

when given a DR $n$, an input context $c$, and a string of individuals $\mathbf{x}$, yields a context with an inert global stratum (containing only the necessary truth true) and a local stratum that states that the $n$-th coordinate of $\mathbf{x}$ is a donkey.

Lastly, the function $\Uparrow: \mathrm{c}_{n, m} \rightarrow \mathrm{c}_{n+m, 0}$ merges the content in both strata into the global stratum, defined as

$$
(\Uparrow c)={ }_{\mathrm{def}} \lambda_{\mathbf{x}}|c| \cdot(\uparrow c \mathbf{x}) \text { and }(\downarrow c \mathbf{x}) \mid \text { true }
$$

where $c$ is a context. Again taking the example context $e$ from Equation (17), merging $e$ gives the context

$$
\left.(\Uparrow e)=\lambda_{x, y} .(\text { farmer } x) \text { and }(\text { donkey } y) \text { and (own } y x\right) \mid \text { true } .
$$

This context merge function $\Uparrow$ is used in the function $\mathrm{cc}: \mathrm{k}_{i, j} \rightarrow \mathrm{k}_{i+j, 0}$, which promotes a proffered content to a context change (again adopting Heim's terminology) if it is accepted by the discourse participants. So for $k$ a content, cc is defined as

$$
(\mathrm{cc} k)={ }_{\mathrm{def}} \lambda_{c} \cdot \Uparrow(k c) \text {. }
$$

As we discuss below, $\Uparrow$ also plays a role in modeling projection.

\subsubsection{Dynamic Connectives}

We follow Martin \& Pollard's (2012) strategy of taking the dynamic existential quantifier, dynamic conjunction and negation as basic and defining all the other connectives in terms of them. The dynamic generalized quantifier EXISTS : $(\omega \rightarrow$ $\left.\mathrm{k}_{i, j}\right) \rightarrow \mathrm{k}_{i, j+1}$ is a multistratal analog of Martin \& Pollard's, where the function $c^{+}={ }_{\text {def }} \lambda_{\mathbf{x}|c|, y} . c$ simply adds the 'next' DR (and lambda binds it):

$$
(\operatorname{EXISTS} D)={ }_{\operatorname{def}} \lambda_{c} \cdot D|c| c^{+}
$$

Note that since EXISTS is used in the meaning of the dynamic indefinite determiner, indefinites introduce lambda bound variables but not existentially bound ones, in a parallel with Heim 1982.

The dynamic conjunction AND : $\mathrm{k}_{i, j} \rightarrow \mathrm{k}_{k, l} \rightarrow \mathrm{k}_{i+k, j+l}$ is also analogous to theirs, but for the multistratal case we need to define a function that composes two contents 
in a way that keeps their strata separate. The function $\odot:(p \times p) \rightarrow(p \times p) \rightarrow$ $(\mathrm{p} \times \mathrm{p})$, defined as

$$
\left(p \mid p^{\prime}\right) \odot\left(q \mid q^{\prime}\right)=_{\operatorname{def}}(p \text { and } q) \mid\left(p^{\prime} \text { and } q^{\prime}\right)
$$

takes care of this, for $\left(p \mid p^{\prime}\right)$ and $\left(q \mid q^{\prime}\right)$ pairs of propositions. Then dynamic conjunction is defined to exhibit the left/right asymmetry of discourse:

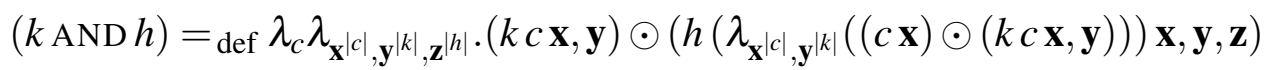

This definition ensures that the second conjunct $h$ is evaluated in a context that includes whatever contributions are made by the first conjunct $k$.

Of the basic connectives, the dynamic negation NOT $: \mathrm{k}_{i, j} \rightarrow \mathrm{k}_{i, 0}$ is the most interesting for our analysis of projection. It is defined so that the local stratum of its argument content $k$ is negated, but its global stratum is left untouched.

$$
(\operatorname{NOT} k)= \begin{cases}\lambda_{c} \lambda_{\mathbf{x}}|c| \cdot(k c) \mathbf{x} \mid \operatorname{not}(\downarrow(k c) \mathbf{x}) & \text { if } \underline{k}=0 \\ \lambda_{c} \lambda_{\mathbf{x}}|c| \cdot \uparrow(k c) \mathbf{x} \mid \operatorname{not}\left(\text { exists }_{\mathbf{y} \underline{k}} \cdot \downarrow(k c) \mathbf{x}, \mathbf{y}\right) & \text { otherwise }\end{cases}
$$

In case $k$ introduces DRs, all of the DRs it introduces are existentially bound so that they are unavailable in future discourse. Negation contains our theory's analog of Heim's (1982) rule of "existential closure," having the effect that the resulting content introduces no local DRs.

\subsection{An Example English Appositive}

Having laid out all of the required formal background, we are in a position to demonstrate our theory's usefulness with a simple English example. In (22), the nominal appositive $a$ donkey projects because the information that Chiquita is one survives negation (cf. (22b)).
a. Chiquita, a donkey, brays.
b. Chiquita, a donkey, doesn't bray.

The multistratal semantics we present here predicts the projection in (22) by making sure that the proposition that Chiquita is a donkey ends up in the global stratum for both examples.

To show this, we start by defining the dynamic meanings of all of the component words. With donkey already defined in Equation (18), we define bray similarly:

$$
\text { BRAY }={ }_{\text {def }} \lambda_{n c} \lambda_{\mathbf{x}^{|c|}} \cdot \text { true } \mid\left(\text { bray } \mathbf{x}_{n}\right)
$$


A multistratal account of the projective Tagalog evidential 'daw'

where bray is the static property of braying. The proper name Chiquita, a dynamic generalized quantifier (type $\left.\left(\omega \rightarrow \mathrm{k}_{i, j}\right) \rightarrow \mathrm{k}_{i, j}\right)$ defined as

$$
\left(\mathrm{CHIQUiTA}_{i} D\right)={ }_{\mathrm{def}} \lambda_{c} \lambda_{\mathbf{x}}|c| \cdot D \mathbf{x}_{i} \quad i<|c|,
$$

just picks out its natural number parameter $i$ as the DR corresponding to Chiquita and passes it to the dynamic property $D$ (provided $i$ is among the DRs that the input context 'knows about'). A more adequate treatment of names would follow Beaver (2001: §7.5.2) by building a definiteness presupposition into the meaning of Chiquita, but here we are avoiding the complexity associated with modeling presuppositions altogether because they are not central to our account.

Echoing Potts (2005), we next define COMMA : $\left(\omega \rightarrow \mathrm{k}_{i, j}\right) \rightarrow\left(\omega \rightarrow \mathrm{k}_{k, l}\right) \rightarrow$ $\left(\omega \rightarrow \mathrm{k}_{i+j+k, l}\right)$, to set apart the appositive content from the rest of the utterance:

$$
\text { COMMA } D E={ }_{\operatorname{def}} \lambda_{n c} \lambda_{\mathbf{x}}|c| \cdot(\Uparrow(D n c) \mathbf{x}) \odot(E n(D n c) \mathbf{x}) .
$$

This function takes two dynamic properties $D$ and $E$ as arguments. The first, $D$, is the appositive content, which has its local stratum merged together with its global stratum via $\Uparrow$, cf. Equation (19). Its second argument, $E$, is then evaluated in a context that has the content of $D$ integrated into it. This is to ensure that any DRs introduced by $D$ are available for anaphoric reference in $E$.

Based on these definitions, the dynamic meaning of (22a) is

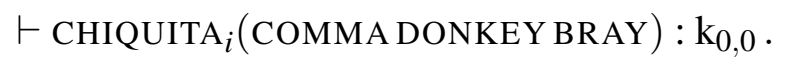

To see that the semantics really does keep the projective content separate, we first $\beta$-reduce the subterm (COMMA DONKEY BRAY), as follows:

$\vdash$ COMMA DONKEY BRAY

$$
\begin{aligned}
& =\lambda_{n c} \lambda_{\mathbf{x}}|c| \cdot(\Uparrow(\text { DONKEY } n c) \mathbf{x}) \odot(\text { BRAY } n(\text { DONKEY } n c) \mathbf{x}) \\
& =\lambda_{n c} \lambda_{\mathbf{x}^{|c|}} \text {.true and }\left(\text { donkey } \mathbf{x}_{n}\right) \mid \text { true } \odot(\operatorname{BRAY} n(\operatorname{DONKEY} n c) \mathbf{x}) \\
& =\lambda_{n c} \lambda_{\mathbf{x}} \text { c| } \text {.true and }\left(\text { donkey } \mathbf{x}_{n}\right) \mid \text { true } \odot \text { true } \mid\left(\text { bray } \mathbf{x}_{n}\right) \\
& \left.\left.=\lambda_{n c} \lambda_{\mathbf{x}|c|} \text {.true and (donkey } \mathbf{x}_{n}\right) \text { and true } \mid \text { true and (bray } \mathbf{x}_{n}\right) \\
& \equiv \lambda_{n c} \lambda_{\mathbf{x}^{|c|} \mid} \cdot\left(\text { donkey } \mathbf{x}_{n}\right) \mid\left(\text { bray } \mathbf{x}_{n}\right): \omega \rightarrow \mathrm{k}_{0,0} \text {, }
\end{aligned}
$$

where $\equiv$ is propositional equivalence 4 (Plummer \& Pollard 2012: §5.3). Then CHIQUITA $_{i}$ takes this dynamic property as argument, finally yielding

$$
\text { (26) } \vdash \operatorname{CHIQUiTA}_{i}(\operatorname{COMMA~DONKEY~BRAY})=\lambda_{c} \lambda_{\mathbf{x}}|c| \cdot\left(\text { donkey } \mathbf{x}_{i}\right) \mid\left(\text { bray }_{i}\right): \mathrm{k}_{0,0}
$$

4 We engage in a mild notational abuse here, since the relation $\equiv$ is between propositions, and so the equivalence is actually between the respective components of the pair of propositions in the body of the term that follows $\equiv$ and their counterparts on the preceding line. 
as the meaning of (22a).

Turning to (22b), we see how the definition of dynamic negation in Equation (21) negates the local stratum but allows the content in the global one to project. Applying NOT to the term from Equation (26), the meaning of (22b) is

$$
\begin{aligned}
& \vdash \operatorname{NOT}\left(\operatorname{CHIQUITA}_{i}(\operatorname{COMMA~DONKEY~BRAY})\right)=(\text { by }(21), \text { case } \underline{k}=0),
\end{aligned}
$$

which negates the proposition that $\mathbf{x}_{i}$ brays, but leaves (donkey $\mathbf{x}_{i}$ ) untouched.

\subsection{Analysis of daw}

We turn to a basic Tagalog example to show how our theory also accounts for the readings observed for daw, as summarized in Table 1.

$$
\begin{aligned}
& \text { Baka tumahol daw si Fido. } \\
& \text { maybe bark.PERF.AV RPT DIR Fido }
\end{aligned}
$$

Our semantics generates both of the scope-taking readings (cf. examples (8) and (9)), and also the two projective readings (cf. examples (8) and (11)). The dynamic meaning of Fido is defined just like CHIQUITA in Equation (24), and tumahol is modeled as a dynamic property similarly to DONKEY and BRAY, above:

$$
\begin{array}{rlrl}
\left(\operatorname{FIDO}_{i} D\right) & ={ }_{\text {def }} \lambda_{c} \lambda_{\mathbf{x}^{|c|}} \cdot D \mathbf{x}_{i} & i<|c| \\
\text { TUMAHOL } & ={ }_{\text {def }} \lambda_{n c} \lambda_{\mathbf{x}^{|c|}} \text {.true } \mid\left(\operatorname{bark} \mathbf{x}_{n}\right) . &
\end{array}
$$

The modal baka is modeled as a unary operation on contents by BAKA : $\mathrm{k}_{i, j} \rightarrow \mathrm{k}_{i, j}$, for $k$ a proffered content:

$$
(\text { BAKA } k)={ }_{\text {def }} \lambda_{c} \lambda_{\mathbf{x}}|c| \cdot \uparrow(k c) \mathbf{x} \mid \operatorname{maybe}(\downarrow(k c) \mathbf{x}) .
$$

Lastly, the direct case marker $s i$ is just the identity function on dynamic generalized quantifiers: (SI $G)={ }_{\text {def }} G$, for $G$ a dynamic generalized quantifier.

As for daw, we model its behavior with two separate definitions, one for the scope-taking cases $\left(\mathrm{DAW}_{S}\right)$ and one for the projective case $\left(\mathrm{DAW}_{P}\right)$, both with the type of unary operations on contents $\mathrm{k}_{i, j} \rightarrow \mathrm{k}_{i, j}$ :

$$
\begin{aligned}
& \left(\operatorname{DAW}_{S} k\right)={ }_{\text {def }} \lambda_{c} \lambda_{\mathbf{x}}|c| \cdot(\uparrow(k c) \mathbf{x}) \mid(\operatorname{report}(\downarrow(k c) \mathbf{x})) \\
& \left(\operatorname{DAW}_{P} k\right)={ }_{\operatorname{def}} \lambda_{c} \lambda_{\mathbf{x}^{|c|}} \cdot(\uparrow(k c) \mathbf{x}) \text { and }(\operatorname{report}(\downarrow(k c) \mathbf{x})) \mid(\downarrow(k c) \mathbf{x}) \text {, }
\end{aligned}
$$

where $k$ is a proffered content. The difference between the two versions of daw is that in the scope-taking $\mathrm{DAW}_{S}$ the report is added to the local stratum, while for the projective $\mathrm{DAW}_{P}$ it ends up in the global one. 
A multistratal account of the projective Tagalog evidential 'daw'

These definitions give rise to all four attested readings for $d a w$. The narrow- and wide-scope readings NS and WS yield a scope interaction between daw and baka in the local stratum.

$$
\begin{aligned}
& \vdash \operatorname{BAKA}\left(\operatorname{DAW}_{S}\left(\operatorname{SIFIDO}_{i} \operatorname{TUMAHOL}\right)\right) \\
& =\lambda_{c} \lambda_{\mathbf{x}}|c| \cdot \operatorname{true} \mid \text { maybe }\left(\operatorname{report}\left(\operatorname{bark}_{i}\right)\right): \mathrm{k}_{0,0} \\
& \vdash \operatorname{DAW}_{S}\left(\operatorname{BAKA}_{\left.\left(\operatorname{SIFIDO}_{i} \operatorname{TUMAHOL}\right)\right)}\right. \\
& =\lambda_{c} \lambda_{\mathbf{x}}|c| \text { true } \mid \operatorname{report}\left(\operatorname{maybe}\left(\operatorname{bark} \mathbf{x}_{i}\right)\right): \mathrm{k}_{0,0}
\end{aligned}
$$

But for the projective readings, no scope interaction takes place.

$$
\begin{aligned}
& \vdash \operatorname{BAKA}\left(\operatorname{DAW}_{P}\left(\text { SIFIDO }_{i} \text { TUMAHOL }\right)\right) \\
& \equiv \lambda_{c} \lambda_{\mathbf{x}^{|c|} \mid} \text {.report }\left(\text { bark } \mathbf{x}_{i}\right) \mid \text { maybe }\left(\operatorname{bark} \mathbf{x}_{i}\right): \mathrm{k}_{0,0} \\
& \vdash \operatorname{DAW}_{P}\left(\text { BAKA } \text { SIFIDO }_{i} \text { TUMAHOL }\right)
\end{aligned}
$$

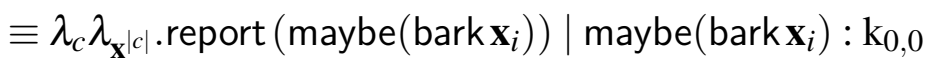

In the $\mathrm{P}$ reading, which corresponds to (11), the report that Fido barked contributes to the global stratum and the proposition that maybe Fido barked contributes to the local stratum. The report projects because it is unmodified by e.g. negation (cf. Equation (21), above). The P' reading is the one that may arise in a situation in which the source of the report is highly trusted, as in the discussion of example (8).

\section{Conclusion}

We have given what we take to be the first conclusive evidence of a projective evidential in any language, the Tagalog reportative evidential $d a w$, based on original fieldwork we conducted. We have also demonstrated that the range of possible readings for daw is dependent on context, a fact not noted in the existing literature on evidentiality. The formal account of $d a w$ we have presented is both dynamic and compositional, is rooted in mainstream type theory, and uses a multistratal approach to capture the difference in behavior between projective and non-projective meanings. It also improves on previous theories of projection because it does not rule out anaphora between strata and allows multiply embedded projection triggers.

In future work, we intend to turn the formal theory presented here into an account of projective meaning more generally. Among other things, this will involve integrating our multistratal semantics with the theory of presupposition in Martin \& Pollard 2012. In order for our account of daw to be fully compositional, we need to specify exactly how the syntax of Tagalog gives rise to the corresponding readings in our semantic theory. We will also investigate both empirical generalizations and a formal encoding of the interaction between the discourse context and daw that often determines which of its possible readings is most prominent. 
Gregory Kierstead and Scott Martin

\section{References}

Amaral, Patricia, Craige Roberts \& E. Allyn Smith. 2007. Review of The Logic of Conventional Implicatures by Chris Potts. Linguistics and Philosophy 30(6). 707-749. doi:10.1007/s10988-008-9025-2.

AnderBois, Scott, Adrian Brasoveanu \& Robert Henderson. 2010. Crossing the appositive/at-issue meaning boundary. In Semantics and Linguistic Theory (SALT) 20, 328-346. CLC Publications.

Andrews, Peter B. 2002. An Introduction to Mathematical Logic and Type Theory: To Truth Through Proof, vol. 27 Applied Logic Series. Kluwer Academic Publishers.

Barendregt, Henk. 1991. Introduction to generalized type systems. Journal of Functional Programming 1(2). 125-154.

Barker, Chris \& Chung-chieh Shan. 2008. Donkey anaphora is in-scope binding. Semantics and Pragmatics 1. 1-42. doi:10.3765/sp.1.1.

Beaver, David I. 2001. Presupposition and Assertion in Dynamic Semantics. CSLI Publications.

Carpenter, Bob. 1997. Type Logical Semantics. MIT Press.

Church, Alonzo. 1940. A formulation of the simple theory of types. Journal of Symbolic Logic 5(2). 56-68. doi:10.2307/2266170.

Faller, Marina. 2002. Semantics and pragmatics of evidentials in Cuzco Quechua: Stanford University dissertation.

Groenendijk, Jeroen \& Martin Stokhof. 1991. Dynamic predicate logic. Linguistics and Philosophy 14(1). 39-100. doi:10.1007/BF00628304.

de Groote, Philippe. 2006. Towards a Montagovian account of dynamics. In Semantics and Linguistic Theory (SALT) 16, 1-16. CLC Publications.

Heim, Irene. 1982. The semantics of definite and indefinite noun phrases: University of Massachusetts, Amherst dissertation.

Henkin, Leon. 1950. Completeness in the theory of types. Journal of Symbolic Logic 15(2). 81-91. doi:10.2307/2266967.

Kamp, Hans. 1981. A theory of truth and semantic representation. In Jeroen Groenendijk, Theo Janssen \& Martin Stokhof (eds.), Formal Methods in the Study of Language, 277-322. Amsterdam: Mathematical Center.

Kroeger, Paul. 1993. Phrase Structure and Grammatical Relations in Tagalog. Stanford, CA: CSLI Publications.

Kubota, Yusuke \& Wataru Uegaki. 2009. Continuation-based semantics for conventional implicatures: The case of Japanese benefactives. In Semantics and Linguistic Theory (SALT) 19, 306-323. CLC Publications.

Lee, Jungmee. 2011. Evidentiality and its interaction with tense: Evidence from Korean: Ohio State University dissertation. 
A multistratal account of the projective Tagalog evidential 'daw'

Lewis, David. 1979. Scorekeeping in a language game. Journal of Philosophical Logic 8(1). 339-359. doi:10.1007/BF00258436.

Lewis, M. Paul (ed.). 2009. Ethnologue: Languages of the world, sixteenth edition. Dallas, TX: SIL International.

Martin, Scott. 2012. Weak familiarity and anaphoric accessibility in dynamic semantics. In Formal grammar (Lecture Notes in Computer Science 7395), 287-306. Springer. doi:10.1007/978-3-642-32024-8.

Martin, Scott \& Carl Pollard. 2012. A higher-order theory of presupposition. Studia Logica 100(4). 727-751. doi:10.1007/s11225-012-9427-6. Special Issue: Logic and Natural Language.

Matthewson, Lisa. 2004. On the methodology of semantic fieldwork. International Journal of American Linguistics 70(4). 369-415. doi:10.1086/429207.

Matthewson, Lisa, Henry Davis \& Hotze Rullman. 2007. Evidentials as epistemic modals: Evidence from St'át'imcets. Linguistic Variation Yearbook 7. 201-254.

McCready, Eric \& Norry Ogata. 2007. Evidentiality, modality and probability. Linguistics and Philosophy 30(2). 147-206. doi:10.1007/s10988-007-9017-7.

Murray, Sarah E. 2010. Evidentiality and the structure of speech acts: Rutgers University dissertation.

Muskens, Reinhard. 1996. Combining Montague semantics and discourse representation theory. Linguistics and Philosophy 19(2). 143-186. doi:10.1007/BF00635836.

Nouwen, Rick. 2007. On appositives and dynamic binding. Research on Language and Computation 5(1). 87-102. doi:10.1007/s11168-006-9019-6.

Plummer, Andrew \& Carl Pollard. 2012. Agnostic possible worlds semantics. In Logical Aspects of Computational Linguistics (LACL) 7 (Lecture Notes in Computer Science 7351), 201-212. Springer.

Potts, Christopher. 2005. The logic of conventional implicatures. Oxford University Press.

Roberts, Craige. 1996. Information structure in discourse: Towards an integrated formal theory of pragmatics. In Papers in Semantics (Working Papers in Linguistics 49), Ohio State University Department of Linguistics. To appear, with a new afterword, in Semantics and Pragmatics, 2012.

van der Sandt, Rob A. 1992. Presupposition projection as anaphora resolution. Journal of Semantics 9(4). 333-377. doi:10.1093/jos/9.4.333.

Schwager, Magdalena. 2010. On what has been said in Tagalog: Reportative daw. In Evidence from Evidentials (University of British Columbia Working Papers in Linguistics 28), 221-246.

Simons, Mandy, Craige Roberts, David Beaver \& Judith Tonhauser. 2010. What projects and why. In Semantics and Linguistic Theory (SALT) 20, 309-327. CLC Publications. 


\section{Gregory Kierstead and Scott Martin}

Gregory Kierstead

222 Oxley Hall

Ohio State University

Columbus, OH 43210 USA

gwk@ling.ohio-state.edu
Scott Martin

222 Oxley Hall

Ohio State University

Columbus, OH 43210 USA

scott@ling.ohio-state.edu 